open access

\section{EDITORES}

- Miguel Oliveira, Jr. (UFAL)

- René Almeida (UFS)

\section{AVALIADORAS}

- Fátima Pessoa (UFPA)

- Cristine Severo (UFSC)

\section{SOBRE OS AUTORES}

- Rosana da Silva Berg Conceptualização, Coleta dos Dados, Análise Formal, Investigação, Escrita - Rascunho Original, Escrita - Análise e Edição.

- Sebastião Josué Votre Conceptualização, Análise Formal, Investigação, Escrita- Rascunho Original, Escrita - Análise e Edição.

\section{DATAS}

- Recebido: 04/08/2021

- Aceito: 23/09/2021

- Publicado: 30/09/2021

\section{COMO CITAR}

BERG, R.S.; VOTRE, S.J. (2021). Impacto das declarações de Nova Delhi, Jomtien, Dakar e Incheon nas políticas públicas de educação. Cadernos de Linguística, v. 2, n. 4, e456.

\title{
IMPACTO DAS DECLARAÇÕES DE NOVA DELHI, JOMTIEN, DAKAR E INCHEON NAS POLÍTICAS PÚBLICAS DE EDUCAÇ̃̃̃O
}

\author{
Rosana da Silva BERG (ID \\ Centro Universitário Augusto Motta (UNISUAM) \\ Sebastião Josué VOTRE (ID \\ Universidade Federal do Rio de Janeiro (UFRJ)
}

RESUMO

Documentos internacionais que traçam metas para a educação de países em desenvolvimento são conhecidos como declarações. Essas declarações são documentos fundadores e têm impacto na educação, como fontes de propostas e como recursos práticos de ação. Neste trabalho, fazemos breve relato cronológico, apresentamos e analisamos cinco documentos: Jomtien e Nova Delhi, LDB 9394/96 e, posteriormente, Dakar e Incheon. Para isso, adotamos a metodologia da análise de conteúdo de Bardin (2016). O referencial teórico apoia-se em Votre (2019) para análise do discurso e Oliveira (2016) para políticas linguísticas. Os primeiros resultados das análises apresentam que o objetivo dos documentos é orientar as políticas públicas para educação dos países em desenvolvimento, a fim de executar o projeto de educação para todos estabelecido em Jomtien, que foi se desdobrando ao longo dos anos até chegar a Incheon, que orienta que a educação não pode deixar ninguém para trás. A análise leva também a um exercício de autocrítica responsável, para os profissionais da linguagem que atuam com educação, no quadro brasileiro, uma vez que, da leitura e releitura das declarações, emerge uma nova preocupação, relativa ao silenciamento e 
à proibição de uso das línguas de grupos minoritários, bem como de imigrantes, que são alijados de sua cultura, a pretexto de integração na cultura monolíngue dos países em que vivem.

\section{ABSTRACT}

International documents dealing with goals of education in developing countries are known as declarations. These declarations are founder documents with impact in public policies, as sources of proposals and as practical resources for action. In this study, we write a succinct report and analysis of five documents: Jomtien, Nova Delhi, LDB 9394/96 and, finally, Dakar and Incheon. We use the method of content analysis, proposed by Bardin (2011). Our theoretical support comes from Votre (2019) for discourse analysis, and Oliveira (2015), for linguistic policies. First results of analysis show that the goal of the documents is to guide public policies for education in developping countries, in order to implement the project of education for all, established in Jomtien, which has evolved, year by year, up to the Declaration of Incheon, in which one reads that nobody can be left without education. We also produce a consistent exercise of responsible criticism, as professionals of language working with education, in the Brazilian context, since the reading and rereading of declarations implies a new preoccupation of silencing, and restriction towards the use of languages of minor groups, as well as of immigrants, who are put apart from their cultures, under the pretext of getting integrated in the monolingual culture of the countries where they live.

\section{PALAVRAS-CHAVE}

Políticas Públicas; Políticas Linguísticas; Documentos Fundadores; Análise do Discurso.

\section{KEYWORDS}

Public Policies; Linguistic Policies; Founder Documents;

Discourse Analysis. 


\section{INTRODUÇÃO'}

A principal esperança da sociedade brasileira é a educação, porque abre portas para o desenvolvimento individual do cidadão, contribui para a formação de pessoas mais tolerantes e conscientes de seus direitos e deveres e provoca transformações positivas nas expectativas da sociedade. Em virtude disso, o debate sobre uma escola planejada para proporcionar ensino de qualidade, que respeite a heterogeneidade e a individualidade dos membros da comunidade escolar e assegure uma educação equitativa e emancipadora para todos faz parte das pautas de políticas públicas para a educação brasileira.

Com foco nas políticas públicas e linguísticas, este trabalho tem por objetivo apresentar e comentar nossa Lei de Diretrizes e Bases da Educação (LDB) 9394/1996 e as declarações internacionais de Nova Delhi, Jomtien, Dakar e Incheon, que orientam a educação dos países em desenvolvimento.

O Brasil, que teve sua primeira Instituiçãa de Ensino Superior há pouco mais de dois séculos (1808), vem envidando esforços para atingir uma educação de qualidade e equitativa. Nossa última LDB (1996) reflete o esforço para que tenhamos uma educação que acolha estudantes das classes menos favorecidas e promova políticas de permanência desses estudantes tanto na educação básica, quanto na universidade, com vistas à felicidade pessoal e à realização profissional.

É consenso que a educação é a base para o desenvolvimento de uma sociedade melhor e mais justa, mais democrática, menos desigual. "A educação é um direito humano, um poderoso motor de desenvolvimento e um dos mais fortes instrumentos para reduzir a pobreza e melhorar a saúde, a igualdade de gênero, a paz e a estabilidade" (BANCO MUNDIAL, 2021). O avanço de um país dependerá do investimento que é feito para alcançar uma educação de qualidade para seus cidadãos.

\section{SUPORTE AO MÉTODO DE ANÁLISE}

Elegemos as quatro declarações: Jomtien, Nova Delhi, Dakar e Incheon para analisar, pois são documentos que têm como objetivo orientar as ações para uma educação básica que dê oportunidade de crescimento social e econômico aos estudantes sem distinção. Esses documentos também são analisados na tese de doutorado sobre a qual nosso trabalho faz referência.

\footnotetext{
1 Parte dos resultados deste trabalho faz parte da tese de doutorado do programa de Políticas Públicas e Formação Humana - UERJ que investiga o capital cultural nas avaliações ENEM e ENADE e será defendida por Rosana as Silva Berg neste ano, sob orientação de Raquel Villardi e coorientação de Sebastião Votre.
} 
A análise preliminar indica que a centralidade dos documentos está na ideia de promover uma educação equitativa que acolha estudantes de classes distintas, para que todos tenham chances de progredir na vida escolar, acadêmica, social e econômica.

Além dos quatro documentos, também faremos breve análise da lei Diretório dos índios, de 1775, em que o rei de Portugal obriga o uso da língua portuguesa e proíbe a língua geral na colônia brasileira, e da LDB 9394/1996, por ter sido promulgada após as primeiras declarações: Jomtien e Nova Delhi.

A análise foi empiricamente orientada, com foco na observação assistemática do corpus que foi varrido com o objetivo de destacar as passagens mais fundamentais para o nosso trabalho. Seguimos o proposto por Bardin (2016), que se organiza nos seguintes polos: "a pré-análise; a exploração do material; o tratamento dos resultados, a inferência e a interpretação" (p. 126). No caso de passagens com ideias repetidas, ou muito parecidas, optamos por apenas uma para fazer parte da análise.

Passamos então à leitura circunstanciada de cada excerto destacado, procurando marcas que nos permitissem confirmar o que nosso suporte teórico postula. Ancoramos nossa proposta na análise do discurso de Votre (2019), que propõe a análise crítica com foco na recepção, focalizando o "leitor como produtor de sentido e como crítico do que percebe como disfuncional, confuso ou inconsequente nos enunciados que examina" (p. 93), e na política linguística de Oliveira (2015), que diz que na política linguística "são tomadas decisões sobre as línguas e realizadas ações sobre as línguas, isto é, que as línguas são também moldadas pela intervenção humana" (p.383).

Introduzimos também breves considerações sobre políticas linguísticas, como área relativamente recente de abordagem da cultura e da educação na perspectiva das potencialidades da língua na formação da consciência, na acepção de Volochinov (2017). A primeira constatação desta nova área de investigação sobre políticas públicas educacionais é que favorecer o florescimento linguístico é garantir a pujança da cultura associada a cada língua que é valorizada, na alfabetização, na produção literária, na política, nos negócios, nos templos.

No Brasil, assistimos a movimentos glotocidas, em relação às línguas indígenas, e de silenciamento de línguas estrangeiras, desde a promulgação da Lei do Diretório, de 7 de junho de 1757, sob a ordem do Marquês de Pombal, a mando de Dom José I.

Ao mesmo tempo que expulsou os jesuítas da colônia, a lei proibiu o uso da língua geral, que era falada por $90 \%$ da população, e das demais línguas indígenas, e impôs o domínio da língua portuguesa. A justificativa do glotocídio e da imposição da língua portuguesa é muito clara, na primeira parte do parágrafo sexto da lei, transcrito a seguir. Segundo a lei, a experiência mostra que, ao introduzir nos domínios a língua do Príncipe, se implanta neles o afeto, a veneração e a obediência ao Príncipe. A lei condena o uso da língua geral, abominável e diabólica, que manteve os índios em rústica e bárbara sujeição. A política 
pública em relação à língua geral e às demais línguas indígenas é explícita: "desterrar o perniciosíssimo abuso, estabelecer o uso da língua portuguesa, sem consentir com o uso da língua geral ou de outras línguas indígenas".

\begin{abstract}
Sempre foi máxima inalteravelmente praticada em todas as nações, que conquistaram novos domínios, introduzir logo nos povos conquistados o seu próprio idioma, por ser indisputável, que este é um dos meios mais eficazes para desterrar dos povos rústicos a barbárie dos seus antigos costumes; e ter mostrado a experiência, que ao mesmo passo, que se introduz neles o uso da língua do príncipe, que os conquistou, se lhes radica também o afeto, a veneração, e a obediência ao mesmo príncipe. Observando pois todas as nações polidas do mundo este prudente, e sólido sistema, nesta conquista se praticou tanto pelo contrário, que só cuidarão os primeiros conquistadores estabelecer nela o uso da língua, que chamaram geral; invenção verdadeiramente abominável, e diabólica, para que privados os índios de todos aqueles meios, que os podiam civilizar, permanecessem na rústica, e bárbara sujeição, em que até agora se conservavam. (§ 6)
\end{abstract}

O conteúdo do artigo 6 da lei revela a filosofia política do rei Dom José, déspota esclarecido, sobre a relevância de manter em seus domínios uma fé, uma lei e uma língua, de modo a garantir a fidelidade e o amor à cultura, aos valores religiosos e políticos do reino de Portugal.

Passemos agora à análise e discussão sucintas dos enunciados introdutórios da lei brasileira e dos quatro documentos internacionais de educação para todos.

\title{
2. LDB 9394/1996 E DECLARAÇÕES INTERNACIONAIS
}

O contexto da produção de cada uma das declarações é o da busca de consenso entre pessoas empoderadas, como representantes de suas nações. São profissionais de educação e de formulação de políticas públicas voltadas à educação para todos. As propostas são detidamente estudadas e aplicadas em cada país signatário. As reformas educacionais refletem e refratam o conteúdo e o espírito das políticas públicas que os países adotam, a partir do que consta nas declarações.

Nesta seção faremos análise da nossa última LDB e das declarações: Jomtien, Nova Delhi, Dakar e Incheon. Seguiremos a ordem cronológica em que os textos foram publicados. Começaremos pela declaração de Jomtien (1990), depois analisaremos Nova Delhi, em seguida a LDB 9394 (1996), depois Dakar e Incheon.

A LDB 9394/1996 foi promulgada após a participação do Brasil em Jomtien e Nova Delhi (1993) e que, por isso, traz em seu texto as ideias desses documentos. O Brasil foi signatário das duas declarações que se concentram na educação para todos. 


\subsection{DECLARAÇÃO MUNDIAL DE EDUCAÇÃO PARA TODOS - DECLARAÇÃO DE JOMTIEN}

Organizada pela UNESCO, a Conferência Mundial sobre Educação para Todos (EPT) foi realizada de 5 a 9 de março de 1990, em Jomtien, Tailândia, e gerou a Declaração Mundial de Educação para Todos: Satisfação das Necessidades Básicas de Aprendizagem (Declaração de Jomtien).

Tendo como principais motivações questões econômicas e educacionais, a declaração destaca a importância da educação básica e estabelece compromissos mundiais para garantir a todas as pessoas os conhecimentos necessários a uma vida digna, visando a uma sociedade mais humana e mais justa, tendo como foco os países menos desenvolvidos.

No início do preâmbulo, o documento diz que há mais de quarenta anos a Declaração Universal dos Direitos Humanos afirma que "toda pessoa tem direito à educação", mas que o cenário da educação mundial ainda apresenta uma realidade excludente que impede a sociedade de enfrentar problemas que geram a exclusão social.

Para avançar rumo à resolução dos problemas citados, a Declaração de Jomtien assevera que a educação "embora não seja condição suficiente, é de importância para o progresso pessoal e social". E a meta é conquistar "um mundo mais seguro, mais sadio, mais próspero e ambientalmente mais puro", além de favorecer o "progresso social, econômico e cultural, a tolerância e a cooperação internacional”. Segundo o documento, para a realização desses objetivos, é necessário garantir a educação básica para os que não têm acesso a ela.

Os educadores e cientistas da educação reunidos em Jomtien seguem princípios claros de atenção básica aos instrumentos essenciais para aprendizagem, o que contempla a primazia da diversidade étnica e política e os movimentos pela recuperação das políticas públicas.

A ideia de educação para a vida toda e a insistência em projetos que facultem a continuidade da aprendizagem repousa, inevitavelmente, nos pressupostos de respeito às peculiaridades culturais locais, às diferentes orientações das pessoas e na adequação de políticas públicas aos interesses dos grupos a serem atendidos pelos projetos educacionais. Nos termos do artigo 1 da declaração:

\footnotetext{
Cada pessoa - criança, jovem ou adulto - deve estar em condições de aproveitar as oportunidades educativas voltadas para satisfazer suas necessidades básicas de aprendizagem. Essas necessidades compreendem tanto os instrumentos essenciais para a aprendizagem (como a leitura e a escrita, a expressão oral, o cálculo, a solução de problemas), quanto os conteúdos básicos da aprendizagem (como conhecimentos, habilidades, valores e atitudes), necessários para que os seres humanos possam sobreviver, desenvolver plenamente suas potencialidades, viver e trabalhar com dignidade, participar plenamente do desenvolvimento, melhorar a qualidade de vida, tomar decisões fundamentadas e continuar aprendendo. A amplitude das necessidades básicas de aprendizagem e a maneira de satisfazê-las variam segundo cada país e cada cultura, e, inevitavelmente, mudam com o decorrer do tempo. (p.2)
} 
Os participantes da Conferência Mundial sobre Educação para Todos defenderam o direito à educação básica para todos e comprometeram-se a colaborar com a adoção de medidas individuais e coletivas para cumprir a meta estabelecida. Para tanto, a declaração proclamou em seus 10 artigos o percurso que contribuiria para que a educação básica fosse direito de todos.

Cada artigo tem um objetivo. Satisfazer às necessidades de aprendizagem na educação básica é o objetivo do primeiro artigo, que destaca a leitura e a escrita, a expressão oral, o cálculo e a solução de problemas como instrumentos essenciais para a aprendizagem; o segundo artigo recomenda que é preciso expandir o enfoque da educação básica e o terceiro tem como objetivo universalizar o acesso à educação e promover a equidade na educação.

Concentrar a atenção na aprendizagem e ampliar os meios e o raio de ação da educação básica são os objetivos dos artigos quarto e quinto que enfatizam a importância de a educação básica estar focada nos resultados efetivos de aprendizagem e nas constantes mudanças das necessidades básicas de aprendizagem de crianças, jovens e adultos. Já o quinto artigo ressalta a importância dos programas de alfabetização, uma vez que ler e escrever são capacidades necessárias para o desenvolvimento de outras habilidades e para o fortalecimento da identidade cultural.

Uma vez que a aprendizagem não acontece em situação de isolamento, o sexto artigo tem como objetivo propiciar um ambiente adequado à aprendizagem o o sétimo fala sobre fortalecer as alianças e esclarece que a obrigação de proporcionar a educação é dever das autoridades: nacional, estadual e municipal.

Desenvolver uma política contextualizada de apoio e mobilizar os recursos são os requisitos para garantir educação para todos, apresentados nos artigos oitavo e nono. $\mathrm{O}$ primeiro faz referência às políticas de apoio dos setores social, cultural e econômico e o segundo diz que "será essencial mobilizar atuais e novos recursos financeiros e humanos, públicos, privados ou voluntários", pois investir recursos na educação básica é o que se pode fazer de mais importante para o país.

Fortalecer a solidariedade internacional é o objetivo do décimo artigo uma vez que, cumprir "as necessidades básicas de aprendizagem constitui-se uma responsabilidade comum e universal a todos os povos, e implica solidariedade internacional" para corrigir disparidades econômicas.

A proposta de empoderamento da sociedade de aprendizagem apresentada em Jomtien passa pelo atendimento a suas necessidades educacionais básicas. As pessoas atendidas de forma adequada em sua formação, crescem em responsabilidade, responsividade e apreço a suas heranças cultural, linguística e espiritual. 
O resultado salutar do investimento em educação de qualidade nos termos de Jomtien garante aos aprendizes o alargamento do círculo do nós, a ampliação da capacidade de conviver com os diferentes, de favorecer a harmonia na convivência entre os diferentes.

\footnotetext{
A satisfação dessas necessidades confere aos membros de uma sociedade a possibilidade e, ao mesmo tempo, a responsabilidade de respeitar e desenvolver sua herança cultural, linguística e espiritual, de promover a educação de outros, de defender a causa da justiça social, de proteger o meio-ambiente e de ser tolerante com os sistemas sociais, políticos e religiosos que difiram dos seus, assegurando respeito aos valores humanistas e aos direitos humanos comumente aceitos, bem como de trabalhar pela paz e pela solidariedade internacionais em um mundo interdependente. (p.3)
}

O Brasil estava representado na conferência e abraçou plenamente os objetivos da Declaração de Jomtien: a universalização do acesso escolar, o financiamento e o repasse de recursos financeiros, a descentralização da gestão. Cabe perguntarmos em que proporção as autoridades educacionais do país estão incorporando os princípios de Jomtien em suas políticas públicas voltadas para a educação, de modo a favorecer o desenvolvimento pleno das capacidades culturais, linguísticas e espirituais de sua população.

\subsection{DECLARAÇÃO DE NOVA DELHI SOBRE EDUCAÇÃO PARA TODOS}

A Declaração de Nova Delhi (1993) ratifica o compromisso de tornar universal a educação básica firmado na Conferência Mundial de Jomtien sobre Educação para Todos.

Os signatários da declaração são representantes de nove países em desenvolvimento que, juntos, possuem a maior parte da população mundial: Indonésia, China, Bangladesh, Brasil, Egito, México, Nigéria, Paquistão e Índia.

Os especialistas desses países reconhecem que suas aspirações e metas de desenvolvimento só serão atingidas quando houver a garantia da educação para todos; reconhecem também que, apesar de ter havido progressos importantes na educação, ainda se fazem necessários mais esforços para oferecer uma educação de qualidade a todos. Para tanto, é preciso que os métodos de educação sejam desenvolvidos para atender às necessidades básicas de aprendizagem dos indivíduos e que toda a sociedade esteja envolvida nessa tarefa.

Afirmam estarem cientes "do papel vital que a educação terá que cumprir no desenvolvimento das nossas sociedades" e asseguram avanços até o ano de 2000, garantindo: uma vaga em escola a todas as crianças; o empenho na educação de jovens e adultos; a eliminação de disparidades por causa de sexo, idade, renda familiar, diferenças culturais, étnicas e linguísticas, e distância geográfica; propõem o aperfeiçoamento dos conteúdos educacionais e o material didático; o treinamento e as condições de trabalho do magistério; a mobilização de setores da sociedade em prol da educação para todos. 
Convocam colaboradores internacionais e instituições financeiras internacionais a ampliarem os investimentos em educação, para que os países possam "sustentar seu desenvolvimento socioeconômico".

Nova Delhi retoma o passado, como ponto de referência para o que já se conseguiu, na educação para todos, e no que urge conseguir. Baseia sua agenda na declaração dos direitos do homem e nas constituições de cada um dos países participantes da Declaração e assevera em seu primeiro artigo:

\begin{abstract}
Nós, os líderes dos nove países em desenvolvimento de maior população do mundo, reiteramos por esta Declaração nosso compromisso de buscar com zelo e determinação as metas definidas pela Conferência Mundial sobre Educação para Todos e pela Cúpula Mundial da Criança, realizadas em 1990, de atender às necessidades básicas de aprendizagem de todos os nossos povos tornando universal a educação básica e ampliando as oportunidades de aprendizagem para crianças, jovens e adultos. Assim fazemos com consciência plena que nossos países abrigam mais do que a metade da população mundial e que o sucesso de nossos esforços é crucial à obtenção da meta global de educação para todos.
\end{abstract}

Os países em desenvolvimento que são signatários de Nova Delhi assumem o compromisso corajoso de "buscar com zelo e determinação" cumprir as metas de Jomtien até o ano de 2000, o que supõe foco no desenvolvimento cultural, espiritual e linguístico das suas populações.

Em 1993, a educação básica brasileira ainda era regida pela Lei Diretrizes e Bases da Educação (LDB) 5692/1971 promulgada pelo governo militar. A 5692 reformou o ensino fundamental (primeiro grau) e o ensino médio (segundo grau). Essa reforma alterou consideravelmente a estrutura do ensino que estava em vigor: dividiu a educação básica em primeiro e segundo graus, privilegiando seu foco para formação de mão de obra para o trabalho.

No artigo segundo os signatários de Nova Delhi aceitam e reconhecem oito itens que merecem registro e comentário: a garantia da educação como condição sine qua non para atender as metas de desenvolvimento; a garantia da educação como instrumento preeminente da promoção dos valores mais relevantes; a necessidade de enfoques criativos nos sistemas formais e informais; a necessidade de conteúdos e métodos se ajustarem ao propósito de empoderamento das pessoas; a necessidade de ações complementares, no âmbito da família e da comunidade, nas áreas de maior carência; a necessidade de priorizar educação de qualidade para mulheres jovens e adultas; o enfrentamento responsável do ônus da pressão demográfica precisa ser encarado de forma responsável; por fim, os signatários reconhecem que o compromisso com a educação de qualidade é de todos os órgãos, públicos, privados e organizações da sociedade civil.

Conforme podemos verificar pela leitura do item 2, desdobrado abaixo em oito subitens, todos eles são de extrema relevância e merecem ser contemplados e atendidos. Alguns dos oito itens merecem um comentário especial. O item 2.1 condiciona o alcance das 
metas de todos os direitos à educação. O item 2.3 interpela os agentes educacionais para inovarem e criarem novas formas de ação educativa. O item 2.4 concentra a ação nas necessidades básicas das populações mais pobres do planeta. Faz-se um reconhecimento especial do papel das famílias e das comunidades para atender as pessoas mais necessitadas, em especial as crianças pequenas.

2.1 as aspirações e metas de desenvolvimento de nossos países serão atendidas somente através da garantia de educação para todos os nossos povos, direito este assegurado tanto pela Declaração Universal dos Direitos do Homem quanto pelas constituições e leis de cada um de nossos países:

2.2 a educação é o instrumento preeminente de promoção dos valores humanos universais, da qualidade dos recursos humanos e do respeito pela diversidade cultural;

2.3 os sistemas educacionais dos nossos países já alcançaram progressos importantes na oferta de educação a contingentes substanciais da nossa população, mas ainda não foram plenamente sucedidos os esforços de proporcionar uma educação de qualidade a todos os nossos povos, o que indica a necessidade de desenvolvermos enfoques criativos tanto dentro quanto fora dos sistemas formais;

2.4 os conteúdos e métodos de educação precisam ser desenvolvidos para servir às necessidades básicas de aprendizagem dos indivíduos e das sociedades, proporcionando-lhes o poder de enfrentar seus problemas mais urgentes - combate à pobreza, aumento da produtividade, melhora das condições de vida e proteção ao meio ambiente - e permitindo que assumam seu papel por direito na construção de sociedades democráticas e no enriquecimento de sua herança cultural;

2.5 os programas educacionais bem sucedidos exigem ações complementares e convergentes, no contexto do papel da família e da comunidade, nas áreas de nutrição adequada, cuidados efetivos da saúde e cuidado e desenvolvimento apropriado para crianças pequenas;

2.6 a educação e a incorporação plena de mulheres jovens e adultas à sociedade são metas importantes em si e elementos chaves do processo de desenvolvimento do bem-estar social, da educação de gerações presentes e futuras e da diversificação das opções disponíveis à mulher para o desenvolvimento de todo o seu potencial;

2.7 pressões demográficas impõem um ônus por demais pesado à capacidade dos sistemas educacionais e impedem as reformas e melhorias necessárias; além do mais, dada a estrutura etária dos nossos países, esse processo continuará no decorrer da próxima década;

2.8 a educação é - e tem que ser - responsabilidade da sociedade, englobando igualmente os governos, as famílias, as comunidades e as organizações não-governamentais, exige o compromisso e a participação de todos numa grande aliança que transcenda a diversidade de opiniões e posições políticas.

A declaração de Nova Delhi, produzida num país continental, com enorme diversidade linguística e étnica, destaca a relevância da diversidade cultural e linguística. Em estreita colaboração com os movimentos ambientalistas, opta pela atenção imediata e urgente para a gestão sustentável dos recursos naturais, com efeito imediato na qualidade da nutrição infantil.

\subsection{A LDB $9394 / 1996$}

O fim dos governos militares no Brasil, em meados da década de 1980, criou um contexto favorável à promulgação de nova LDB. Contudo, a lei que os profissionais de educação e sociedade desejavam só foi promulgada em 1996.

Antes disso, educadores e associações docentes promoveram encontros para manifestar o tipo de educação que esperavam que a nova lei promovesse. Um desses encontros foi a IV Conferência Brasileira de Educação, realizada de 02 a 05 de setembro 
de 1986, em Goiânia. Do evento resultou a Carta de Goiânia, documento que apresentava proposta para o capítulo dedicado à educação da nova Carta Constitucional que estava sendo gestada, uma vez que o Brasil estava em processo de redemocratização.

Na Carta de Goiânia lia-se que, em decorrência de políticas governamentais incapazes de promover a justiça social, o país continuava convivendo com problemas crônicos referentes à universalização e qualidade do ensino. O documento também destacou que os seguintes dados revelavam a situação da educação no país:

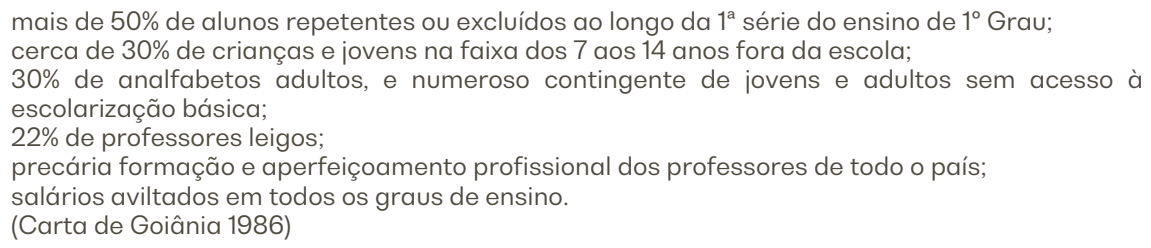

Com base na Carta de Goiânia, podemos avaliar que a educação, enquanto esteve sob o comando dos governos militares, avançou pouco e não conseguiu fazer ecoar o verso da propaganda institucional do governo federal que dizia, "esse é um país que vai pra frente". Dez anos após a Conferência de Goiânia, a atual LDB foi promulgada.

Além de deixar claro que houve pouco avanço na educação brasileira durante os governos militares, a Carta de Goiânia traz em seu texto a necessidade de o Brasil investir em políticas públicas que promovessem a justiça social e em decorrência disso uma educação de qualidade que fosse oferecida também aos estudantes das classes vulneráveis, o que foi confirmado em Jomtien e Nova Delhi.

A LDB que a sociedade e os educadores esperaram por mais de dez anos foi promulgada em 1996. A 9394/96 recomenda, no seu primeiro artigo, que "a educação escolar deverá vincular-se ao mundo do trabalho e à prática social” (§̧ $2^{\circ}$ ) e, nos $2^{\circ}$ e $3^{\circ}$ artigos, estabelece que a educação deve ser baseada nos princípios de liberdade, nos ideais de solidariedade humana, em igualdade de condições, tendo por objetivo o pleno desenvolvimento do educando para a cidadania e para o trabalho.

As palavras liberdade, solidariedade e o espírito de educação democrática voltam a aparecer no texto da LDB brasileira.

Em 2013, a lei 12.796 alterou alguns dispositivos da 9394; entre essas alterações está a do item I, artigo $4^{\circ}$, que diz que a educação básica obrigatória e gratuita passou a ser organizada da seguinte forma: pré-escola, ensino fundamental e ensino médio, e estabeleceu a faixa etária da educação básica dos 4 (quatro) aos 17 (dezessete) anos, ampliando o tempo de obrigatoriedade de permanência na escola.

Segundo o artigo $9^{\circ}$, a União deverá, em colaboração com os Estados, o Distrito Federal e os Municípios, elaborar o Plano Nacional de Educação, os currículos e seus conteúdos mínimos, de modo a assegurar formação básica comum e estabelecer um 
processo nacional de avaliação do rendimento escolar no ensino fundamental, médio e superior, objetivando a definição de prioridades e a melhoria da qualidade do ensino. Esse artigo da LDB ampara e acolhe criação de um sistema brasileiro de avaliações em larga escala e reflete a participação do Brasil no que foi pactuado nas Declarações de Jomtien e Nova Delhi.

A 9394/96 define os papéis de todos os envolvidos na educação e trata o ensino médio como uma etapa final da educação básica, que deverá consolidar e aprofundar os conhecimentos adquiridos no ensino fundamental (Art. 35). Sobre preparar o estudante profissionalmente no ensino médio, versa que "poderá prepará-lo para o exercício de profissões técnicas" (Art. 36 §ु $2^{\circ}$ ).

No artigo 26, a lei indica a necessidade de um núcleo comum, apesar de as redes de ensino terem liberdade de organização:

\footnotetext{
Os currículos da educação infantil, do ensino fundamental e do ensino médio devem ter base nacional comum, a ser complementada, em cada sistema de ensino e em cada estabelecimento escolar, por uma parte diversificada, exigida pelas características regionais e locais da sociedade, da cultura, da economia e dos educandos. (BRASIL, 1996)
}

A LDB 9394/96 tem importância crucial nas transformações ocorridas na educação brasileira desde a sua promulgação. É a lei que amplia os direitos educacionais e a autonomia de ação das redes públicas, das escolas e dos professores e deixa mais claras as atribuições do trabalho docente. Além disso, estabelece que o foco deve ser o preparo do educando; a lei apresenta, entre os princípios sob os quais o ensino deve ser ministrado, a "liberdade de aprender, ensinar, pesquisar e divulgar a cultura, o pensamento, a arte e o saber" (Art. $2^{\circ}$ ), deslocando o foco do ensino para a aprendizagem.

A lei incorpora os princípios da Constituição Cidadã de 1988 e acolhe as orientações pedagógicas de seu principal elaborador, o antropólogo e educador Darcy Ribeiro. Abre espaço para a diversidade cultural e étnica, indispensáveis num país continental, em que a miscigenação é a marca do povo, e em que a diversidade cultural, étnica e linguística, é amordaçada, desde a lei do diretório, de 1757, que estabelece a língua portuguesa como única no território nacional, apesar de contarmos com mais de 200 línguas indígenas.

Os estudiosos de políticas públicas relacionadas à educação linguística convivem com o problema decorrentes da ausência de movimentos em prol da recuperação e do planejamento linguístico para minorias. Na América Latina, é sintomático que apenas no Paraguai e na Bolívia se tenha registrado movimento em favor do guarani como segunda língua nacional, enquanto línguas como quéchua e o aimará sejam consideradas como línguas locais.

Os princípios em que se apoia a lei privilegiam igualdade de condições para o acesso e para o ensino-aprendizagem. Privilegiam a diversidade cultural e étnica, o que inclui, também, a oportunidade das etnias para serem alfabetizadas em suas próprias línguas e 
em sua própria cultura. Oferecem garantia de que todos serão tratados com igualdade, independentemente de seus sistemas de crenças, orientações e práticas.

O texto da LDB 9394/96 repercute os objetivos das declarações de Jomtien e de Nova Delhi no que tange uma educação democrática e inclusiva.

\title{
2.4. DECLARAÇÕES DE DAKAR E INCHEON
}

Dez anos após publicação da Declaração de Jomtien, o Fórum Mundial da Educação se reuniu no Senegal para avaliar quais eram os compromissos assumidos em 1990 que a educação global havia atingido quando foi publicada a declaração de Dakar que é um documento importante, por estabelecer novas metas para a educação global.

Em 2015, o Fórum Mundial da Educação gerou a Declaração de Incheon inspirada nos Objetivos de Desenvolvimento Sustentável (ODS) com especial atenção ao objetivo 4, cuja temática é a educação.

\subsubsection{DECLARAÇÃO DE DAKAR}

A Declaração de Dakar é considerada um marco para a educação global, porque diversos países se comprometeram a atingir os objetivos da Educação para Todos (EPT), estabelecidos no encontro.

No tópico 3 o documento reafirma os compromissos de Jomtien e declara:

\begin{abstract}
We re-affirm the vision of the World Declaration on Education for All (Jomtien 1990), supported by the Universal Declaration of Human Rights and the Convention on the Rights of the Child, that all children, young people and adults have the human right to benefit from an education that will meet their basic learning needs in the best and fullest sense of the term, an education that includes learning to know, to do, to live together and to be. It is an education geared to tapping each individual's talents and potential, and developing learners' personalities, so that they can improve their lives and transform their societies. (p. 8)
\end{abstract}

Os signatários de Dakar pactuaram o compromisso com uma educação orientada para captar o potencial de cada indivíduo com a finalidade de que ele melhore sua vida e a vida em sociedade. Avaliamos ser um compromisso audacioso, pois foca no indivíduo e, para que isso ocorra, é necessária uma educação com foco na aprendizagem em turmas pequenas.

2 Nós reafirmamos a visão da Declaração Mundial de Educação Para Todos (Jomtien, 1990), apoiada pela Declaração Universal de Direitos Humanos e pela Convenção sobre os Direitos da Criança, de que toda as crianças, jovens e adultos têm o direito humano de beneficiar-se de uma educação que satisfaça suas necessidades básicas de aprendizagem, no melhor e mais pleno sentido do termo, e que inclua aprender a aprender, a fazer, a conviver e a ser. É uma educação que se destina a captar os talentos e o potencial de cada pessoa e a desenvolver a personalidade dos educandos para que possam melhorar as suas vidas e transformar as suas sociedades. (Tradução nossa) 
O Marco de Dakar acolheu os acordos firmados pela comunidade internacional para educação básica nos anos 1990, o que mantém a atenção para o desenvolvimento espiritual, cultural e linguístico. O documento avaliou que houve progresso significativo em muitos países, mas apresentou dados que afirmavam que o desafio naquele momento ainda era cumprir os compromissos firmados na década anterior. Entre os dados apresentados estão: mais de 113 milhões de crianças sem acesso ao ensino primário, 880 milhões de adultos analfabetos, discriminação de gênero permeando os sistemas educacionais e a qualidade da aprendizagem e da aquisição de valores, e habilidades humanas que estavam longe das aspirações e necessidades de indivíduos e sociedades. Para dar passos mais largos em direção à Educação Para Todos, o Marco de Dakar estabeleceu as seguintes metas para a educação global:

I. expandir e melhorar o cuidado e a educação da criança pequena, especialmente das mais vulneráveis e em maior desvantagem;

II. assegurar que todas as crianças, com ênfase especial nas meninas e nas crianças em circunstâncias difíceis e pertencentes a minorias étnicas, tenham acesso à educação primária, obrigatória, gratuita e de boa qualidade até o ano 2015;

III. assegurar que as necessidades de aprendizagem de todos os jovens e adultos sejam atendidas pelo acesso equitativo à aprendizagem apropriada e às habilidades para a vida;

IV. alcançar uma melhoria de 50\% nos níveis de alfabetização de adultos até 2015, especialmente para as mulheres, e acesso equitativo à educação básica e continuada para todos os adultos;

V. eliminar disparidades de gênero na educação primária e secundária até 2005 e alcançar a igualdade de gênero na educação até 2015, com enfoque na garantia ao acesso e o desempenho pleno e equitativo de meninas na educação básica de boa qualidade;

VI. melhorar todos os aspectos da qualidade da educação e assegurar excelência para todos, de forma a garantir a todos resultados reconhecidos e mensuráveis, especialmente na alfabetização, matemática e habilidades essenciais à vida.

Das metas, a de número Vlé a que trata das avaliações, pois se compromete a melhorar os aspectos da qualidade da educação e reconhecer e mensurar os resultados. Para que haja a mensuração da aprendizagem dos alunos, é necessário que haja avaliações que apresentem o quanto e como os estudantes estão avançando e se o desempenho desses alunos é equitativo.

Dakar conclamou os países a desenvolver e fortalecer planos nacionais de ação e cumprir os objetivos até 2015. Destacou a importância da cooperação internacional e regional para o financiamento da educação. O documento lista doze ações para que as metas estabelecidas sejam alcançadas. As ações I, II, IV e X refletem o recomendado pelo Banco Mundial, quanto ao financiamento da educação e sua mensuração de resultados. Essas ações dizem: 
I. mobilizar uma forte vontade política nacional e internacional em prol da Educação para Todos, desenvolver planos de ação nacionais e incrementar de forma significativa os investimentos em educação básica;

II. promover políticas de Educação para Todos dentro de marco setorial integrado e sustentável, claramente articulado com a eliminação da pobreza e com estratégias de desenvolvimento;

IV. desenvolver sistemas de administração e de gestão educacional que sejam participativos e capazes de dar resposta e de prestar contas;

X. monitorar sistematicamente o progresso no alcance dos objetivos e estratégias de EPT nos âmbitos internacional, nacional e regional

Sobre gerenciamento da educação, o Banco Mundial diz que:

(...) investe no desenvolvimento de bens públicos globais que podem ser usados pelos países para diagnosticar o funcionamento do sistema educacional e apoiar a implementação de ações para melhorá-lo. (2021)

O Fórum Mundial de Educação em 2000 avaliou o quanto a EPT (1990) havia progredido e estabeleceu estratégias e metas para que os países continuassem trabalhando para o avanço da educação básica, conforme o orientado pelo Banco Mundial.

A análise mostra que Dakar está envolvida com a melhoria das taxas, da expansão dos cuidados com as crianças pequenas, com as meninas, garotas e mulheres que se encontram em dificuldades especiais de aprendizagem. Sinal dos tempos, o documento focaliza esforços para eliminar disparidades de gênero. Acentua também o esforço para eliminar disparidades entre os grupos étnicos.

O documento acena, de forma urgente, para atenção às populações mais pobres do continente africano, que além de alimentos e medicamentos, necessitam de educação de qualidade para todos. Dakar inova, ao propor cifras relacionadas ao alcance das metas educacionais, tanto no tempo quanto na proporção de pessoas a serem atendidas. Contempla com cuidado as minorias étnicas, com a oferta de educação primária obrigatória, o que faz sentido, para uma declaração produzida no continente africano. Destaca a urgência de programas de alfabetização obrigatória, sobretudo para as populações rurais do continente africano. Se levarmos em conta que em vários países africanos há línguas que precisam ser estudadas e descritas, podemos inferir os problemas envolvidos com a alfabetização.

O enunciado da declaração é transparente nos objetivos, conforme se pode ler no item 7:

\footnotetext{
Comprometemo-nos a atingir os seguintes objetivos: I. expandir e melhorar o cuidado e a educação da criança pequena, especialmente das mais vulneráveis e em maior desvantagem; II. assegurar que todas as crianças, com ênfase especial nas meninas e nas crianças em circunstâncias difíceis e pertencentes a minorias étnicas, tenham acesso à educação primária, obrigatória, gratuita e de boa qualidade até o ano 2015; III. assegurar que as necessidades de aprendizagem de todos os jovens e adultos sejam atendidas pelo acesso equitativo à aprendizagem apropriada e às habilidades para a vida; IV. alcançar uma melhoria de $50 \%$ nos
} 
níveis de alfabetização de adultos até 2015, especialmente para as mulheres, e acesso equitativo à educação básica e continuada para todos os adultos; V. eliminar disparidades de gênero na educação primária e secundária até 2005 e alcançar a igualdade de gênero na educação até 2015, com enfoque na garantia ao acesso e o desempenho pleno e eqüitativo de meninas na educação básica de boa qualidade; Vl. melhorar todos os aspectos da qualidade da educação e assegurar excelência para todos, de forma a garantir a todos resultados reconhecidos e mensuráveis, especialmente na alfabetização, matemática e habilidades essenciais à vida. (p.7)

\subsubsection{DECLARAÇÃO DE INCHEON}

Em 2015, na cidade de Incheon, Coreia do Sul, o Fórum Mundial de Educação publicou a Declaração de Incheon. O documento reafirma o movimento EPT iniciado em Jomtien e reitera o Marco de Dakar, afirmando que Jomtien é "o mais importante compromisso com a educação nas últimas décadas, que tem ajudado a promover progressos significativos na educação", bem como a decidir sobre caminhos que, através da educação, melhorem a vida das pessoas.

Os signatários do documento formularam decisões que determinaram ações para "acabar com a pobreza, promover a prosperidade e o bem-estar para todos, proteger o meio ambiente e enfrentar as mudanças climáticas". Nesta reunião foi elaborada uma agenda que deve ser cumprida até 2030. A agenda se divide em 17 Objetivos de Desenvolvimento Sustentável (ODS). O objetivo 4 tem foco na educação e pretende "Assegurar a educação inclusiva e equitativa e de qualidade, e promover oportunidades de aprendizagem ao longo da vida para todas e todos”. Sem educação de qualidade não é possível o desenvolvimento sustentável.

A ODS 4 traça metas para a educação básica que têm como prazo para serem cumpridas o ano de 2030 e afirma que essas metas só serão consideradas cumpridas quando forem atingidas por todos.

A declaração afirma que "a educação é um bem público, um direito humano fundamental e a base que garante a efetivação de outros direitos. Ela é essencial para a paz, a tolerância, a realização humana e o desenvolvimento sustentável".

Nesse excerto, a declaração admite que a educação deve ser protagonista na formação de pessoas que lutem por uma sociedade em que os direitos fundamentais do ser humano sejam garantidos. Além disso, afirma que sem uma educação que invista na autonomia dos estudantes, não será possível formar pessoas que se comprometam com a luta pela paz, pela tolerância, pela realização humana e pelo desenvolvimento sustentável, ou seja, que lutem pela felicidade. Ao referir a necessidade de educação para a autonomia, Incheon atende a um dos princípios básicos da emancipação das pessoas, fortemente defendido pelo educador brasileiro Paulo Freire, que se envolveu com os projetos educacionais internacionais.

Assim como a Declaração de Dakar, Incheon destaca a importância da cooperação financeira internacional para que a educação básica avance rumo ao cumprimento das metas de 2030. O documento convoca os países desenvolvidos e de renda média, os 
doadores tradicionais e emergentes e os mecanismos de financiamento internacional que aumentem os recursos para educação.

Para mensurar os resultados dos investimentos na educação básica o documento diz:

Decidimos desenvolver sistemas de monitoramento e avaliação nacionais abrangentes para produzir evidências sólidas que orientem a formação de políticas e a gestão dos sistemas de educação, e também assegurem a prestação de contas. (UNESCO, 2015, p. 8)

Por estar concentrada na ODS 4, a Declaração de Incheon se compromete com a obtenção de resultados relevantes de aprendizagem e reconhece que há interdependência entre as nações, por isso conclama a todos para participarem "com ações ousadas e inovadoras" da construção de uma educação que transforme vidas.

O documento abre com a formulação corajosa de um compromisso radical, urgente, com agenda holística, quase utópica, dizendo que "Comprometemo-nos, em caráter de urgência, com uma agenda de educação única e renovada, que seja holística, ousada e ambiciosa, que não deixe ninguém para trás."

O caráter ousado e ambicioso se explicita no objetivo 4 do desenvolvimento sustentável, em que se acentua o alto grau de correspondência entre os objetivos de desenvolvimento até 2030 , que firmam posição com as propriedades inclusiva e equitativa, e destacam, corajosamente, que se trata de projeto de educação de qualidade. O comentário oferecido por Incheon ao ODS4 salienta, também, uma inovação surpreendente no alcance das políticas públicas da educação, ao estabelecer o objetivo de promover oportunidades de aprendizagem ao longo da vida, e não mais focalizar as coortes infantojuvenis. Essa nova visão é inteiramente captada pelo ODS 4: "Assegurar a educação inclusiva e equitativa de qualidade, e promover oportunidades de aprendizagem ao longo da vida para todos" e suas metas correspondentes.

É impressionante a franqueza com que os autores da declaração fazem autocrítica e demonstram consciência da necessidade de reequacionar os problemas e os desafios, e de lidar com as questões inacabadas da agenda EPT e ODS: "Com essa visão, transformadora e universal, percebem-se as 'questões inacabadas' da agenda de EPT e ODS relacionadas à educação e também se abordam desafios globais e nacionais da educação.”.

Incheon oferece um lugar de destaque para os valores humanistas da educação e do desenvolvimento, que resultam no mais eficaz ideário que se pode imaginar para o trabalho com as pessoas. A proposta é mandatória na atenção aos direitos humanos, na dignidade humana, com foco na justiça social, na inclusão, na proteção a quem dela precisa.

Merece menção especial o cuidado com a diversidade, desdobrada em cultural, linguística e étnica. É a primeira vez que nos defrontamos com um documento em que, ao lado da diversidade cultural e étnica, ocorre menção explícita à diversidade linguística, o que aponta para a importância das políticas públicas educacionais referentes às línguas, como recurso especial para a integração e o desenvolvimento de grupos étnicos, que 
passam a ter oportunidade de alfabetização em suas próprias línguas, uma vez que a visão do documento "é inspirada por uma visão humanista da educação e do desenvolvimento, com base nos direitos humanos e na dignidade; na justiça social; na inclusão; na proteção; na diversidade cultural, linguística e étnica (...)”.

Na lista das inspirações que guiaram a Declaração de Incheon, a parte final merece menção especial, por atentar para a responsabilidade social dos gestores e na transparência das prestações de contas, que estabelece que sejam compartilhadas "na responsabilidade e na prestação de contas compartilhadas".

Lemos, com a alma em festa, a reafirmação de que não há garantia efetiva dos demais direitos humanos, se as pessoas ficarem privadas do direito à educação, pois a declaração reafirma "que a educação é um bem público, um direito humano fundamental e a base que garante a efetivação de outros direitos".

Continuemos nossos comentários sobre a parte final do parágrafo de abertura de Incheon, que consta de três períodos.

O primeiro assegura que a educação é a garantia da paz e da tolerância, que é a única alternativa para a realização humana, em termos pessoais e profissionais, e sem ela não haverá desenvolvimento sustentável: "Ela (educação) é essencial para a paz, a tolerância, a realização humana e o desenvolvimento sustentável.".

O segundo representa uma inovação impressionante no contexto de desenvolvimento sócio-econômico, ao reconhecer, no fórum mundial, que a educação é uma ferramenta indispensável para a erradicação da pobreza: "Reconhecemos a educação como elementochave para atingirmos o pleno emprego e a erradicação da pobreza.".

Por fim, os signatários de Incheon prometem concentrar esforços para o atingimento dos objetivos referentes a acesso, inclusão e equidade, e sobretudo na qualidade dos resultados da aprendizagem. Compromissos assumidos até 2030 representam uma esperança no projeto de educação ao longo da vida.

\section{CONSIDERAÇÕES FINAIS}

Este trabalho reflete e refrata nosso contato com estudos sobre educação, que nos encaminharam para políticas públicas educacionais, o que nos familiarizou com as declarações internacionais de educação para todos. A reflexão, inevitável, se refere ao grau de incorporação das políticas educacionais nas políticas públicas nacionais, verificada nas leis e demais documentos oficiais relacionados à educação básica. $A$ refração resulta da busca do grau de conformidade das políticas públicas da educação brasileira, em face do que se propõe e se postula nos documentos internacionais. 
Da leitura e releitura das declarações, emerge uma nova preocupação, relativa ao silenciamento e à proibição de uso das línguas de grupos minoritários, bem como de imigrantes, que são alijados de sua cultura, a pretexto de integração no universo monolíngüe dos países em que vivem.

O ano de 1990 foi um marco importante para educação dos países em desenvolvimento. A Declaração de Jomtien deu início a uma série de debates e ações para impulsionar uma educação que inclua também aqueles que, devido à pobreza, têm dificuldades em avançar na escola.

O exame dos documentos mostra que, no curso de 25 anos, firmou-se o discurso das políticas públicas em torno de educação de qualidade para todas as crianças e adolescentes, sem deixar nenhum para trás. As sedes das quatro declarações refletem o interesse dos organismos internacionais de educação em privilegiar realidades geoeducacionais, culturais, linguísticas e econômicas distintas, e focalização progressiva em meninas e garotas, e nas pessoas com mais dificuldade para arcar com os desafios da aprendizagem.

A leitura dos documentos leva a um exercício de autocrítica responsável, para os profissionais da linguagem que atuam com educação, no quadro brasileiro, pois conforme Pasinatto (2019), tentamos subjugar os indígenas, impedindo-os de falar suas línguas, e só recentemente construímos programas de alfabetização em suas línguas. Por outro lado, silenciamos os imigrantes, desfavorecendo o uso de suas línguas de origem, persuadindoos a utilizar somente o português, com a perda irreparável das culturas que estão agregadas às suas línguas maternas.

As declarações sobre educação para todos que acabamos de mencionar permitem postular que o estado da arte da educação é relativamente homogêneo, em termos de metas e objetivos a curto, médio e longo prazo. As leis que aqui mencionamos também estabelecem um quadro homogêneo no que tange a políticas públicas. Todos os documentos pregam o bem-estar e a felicidade dos povos. Povos do mundo, no caso das Declarações, povos do Brasil, no caso das duas leis, o Diretório dos índios de 1755 e a Lei de Diretrizes e Bases, de 1996.

Guiado pelo espírito desses documentos, o Brasil é um país homogêneo, como uma lei, uma política pública e uma política linguística convergentes: apenas uma língua, apenas uma cultura, o que implicou e continua a implicar proibições de outras culturas e de outras línguas, e o silenciamento de tudo que turbe a paz do país, lusitano e cristão. As outras crenças são toleradas, mas com desprezo. As outras línguas, essas não são reconhecidas.

Com política pública da educação e política linguística unitárias, o país se orgulha de ser monocorde, sem dissenções culturais internas. Estamos no contexto perfeito para ouvirmos, de Roland Barthes (1978), que temos uma língua fascista, no sentido que nos obriga a falar segundo os ditames dos gramáticos e liderados pela Academia Brasileira de Letras. O 
enunciado fascista é simples, de estrutura predicativa, apoiado em enunciados fixos, que não reconhecem a origem, como "minha pátria é a língua portuguesa" ou "o povo que habita o Brasil é o povo brasileiro". Os dois enunciados são mandatórios, no sentido de que obrigam as pessoas a terem um comportamento consentâneo e se "ufanem de seu país".

A pergunta com que fechamos este relato de pesquisa é: o que, como educadores, podemos fazer, para nos libertarmos da verdade fascista, aqui enunciada. Retomamos Barthes, com a continuidade da sua reflexão. Contra o fascismo da língua, que obriga a ser e a fazer, e da cultura, que força o comportamento, há alternativas, de quebra do monopólio, pela inovação no modo de dizer e de ser. A própria língua contém, em seu conjunto de princípios e regras, a fonte da renovação. Cabe, a cada usuário, exercitar o modo de se construir, autônomo, no contexto homogeneizante que nos envolve.

Se este final de considerações nos leva à insegurança do que fazer, perguntamos: como diminuirmos o autoritarismo que impregna de ordenações as leis e as declarações sobre educação para todos?

\section{REFERÊNCIAS}

BANCO MUNDIAL. Educação, 2021. disponível em: https://www.worldbank.org/en/topic/education/overview. Acesso 31 mar 2021.

Gerenciamento de educação, 2021. disponível em https://www.worldbank.org/en/topic/education/brief/education-management. Acesso 31 mar 2021

BARDIN, Laurence. Análise de conteúdo. Tradução de Luís Antero Reto e Augusto Pinheiro. São Paulo: Edições 70, 2016.

BARTH, Fredrik. Os grupos étnicos e suas fronteiras. In: BARTH, Fredrik. O guru, o iniciador e outras variações antropológicas, Rio de Janeiro: Contra Capa Livraria, 2000, p. 25-68.

BARTHES, Roland. Aula. São Paulo: Cultrix, 1978

BRASIL. Directorio, que se deve observar nas povoaçoens dos indios do Pará, e Maranhaõ : em quanto Sua Magestade naõ mandar o contrario, 1758. Disponível em: https://www2.senado.leg.br/bdsf/handle/id/518740. Acesso 11 jul 2021.

IV Conferência brasileira de educação - Carta de Goiânia, 1986 Disponível em: http://www.repositorio.ufc.br/handle/riufc/13165. Acesso 11 jul 2021.

Lei $n^{\circ}$ 9.394, de 20 de dezembro de 1996, 1996 disponível em: http://www.planalto.gov.br/ccivil_03/leis/I9394.htm. Acesso 11 jul 2021.

COELHO, Mauro Cezar. A Civilização da Amazônia - Alexandre Rodriques Ferreira e o Diretório dos Índios: a educação de indígenas e luso-brasileiros pela ótica do trabalho, 2007. Disponível em: https://revistas2.uepg.br/index.php/rhr/article/view/2110/159. Acesso 28 jun 2021

Mauro Cezar. O Diretório dos Índios e as Chefias Indígenas: Uma inflexão. Revista Campos, Curitiba, n. 7 (1), 2006, p. 117-134. DOI: http://dx.doi.org/10.5380/cam.v7i1.5444. Acesso 25 junho 2021

OLIVEIRA, Gilvan Müller de. Políticas Linguísticas: uma entrevista com Gilvan Müller de Oliveira, 2016. Disponível: http://www.revel.inf.br/files/e92f933a3b0ca404b70a1698852e4ebd.pdf. Acesso 30 jun 2021 
PASINATTO, Rubiamara. Políticas linguísticas no Brasil: da dominação dos nativos ao silenciamento dos imigrantes. Domínios da lingu@gem, Uberlândia, v. 13, n. 1, p. 149-174, 3 fev. 2019. DOI: https://doi.org/10.14393/DL37-v13n1a20197. Acesso 30 jun 2021

UNESCO. Declaração de Dakar: Educação para todos.

Biblioteca Virtual de Direitos Humanos da USP, 2000. Disponível em:

www.direitoshumanos.usp.br/index.php/Direito-a-Educação/declaracao-de-dakar/lmprimir.html. Acesso 20 fev 2021

Declaração de Incheon, 2015 disponível em: https://inee.org/system/files/resources/245656por.pdf. 2015. Acesso 20 fev 2021

Declaração Mundial de Educação para Todos, 1990. disponível em:

https://www.unicef.org/brazil/declaracao-mundial-sobre-educacao-para-todos-conferencia-de-jomtien-1990. Acesso 11 jul 2021

Declaração de Nova Delhi sobre educação para todos, 1993. disponível em: http://unesdoc.unesco.org/images/0013/001393/139393por.pdf. Acesso 11 jul 2021

The Dakar Framework for Action: Education for All, 2000. Disponível em: https://unesdoc.unesco.org/ark:/48223/pf0000121147. Acesso 14 jul 2021

USP. Diretório que se deve observar nas Povoações dos Índios do Pará, e Maranhão, enquanto Sua Majestade não mandar o contrário, 1997. Disponível em:

http://lemad.fflch.usp.br/sites/lemad.fflch.usp.br/files/2018/04/Diretorio_dos_indios_de\%29_1757.pdf. Acesso 11 jul 2021

VOLOCHINOV, Valentim. Marxismo e filosofia da linguagem. Rio de Janeiro, Editora 34, 2017.

VOTRE. Sebastião Josué. Análise do discurso. São Paulo: Parábola, 2019. 